\title{
Life cycle inventory of a biodiesel production unit in Brazil
}

\author{
Priscilla Sieira ${ }^{1}$, Erick B.F. Galante ${ }^{1, *}$, Wilma A. Gonzales ${ }^{1}$, Assed Haddad ${ }^{2}$ \\ ${ }^{1}$ IME, Dept of Chemical Engineering, Rio de Janeiro, Brazil \\ ${ }^{2}$ UFRJ, Dept of Civil Engineering, Rio de Janeiro, Brazil
}

\section{Email address:}

pri_sieir@hotmail.com (P. Sieira), egalante@ime.eb.br (E. B. F. Galante),d5wilma@ime.eb.br (W.A. Gonzales), assed@poli.ufrj.br (A. Haddad)

\section{To cite this article:}

Priscilla Sieira, Erick B.F. Galante, Wilma A. Gonzales, Assed Haddad. Life Cycle Inventory of a Biodiesel Production Unit. American Journal of Chemical Engineering. Vol. 2, No. 1, 2014, pp. 1-7. doi: 10.11648/j.ajche.20140201.11

\begin{abstract}
Carbon dioxide is one of the main compounds pointed as a cause for climate changes, mainly due to the accelerated use of fossil fuels. In order to measure the consumption of the resources that generate carbon dioxide and verify these compounds emissions, quantitative studies aren't sufficient, but it is needed a proportion relation with the environmental impact. Life cycle analysis studies are used to establish parameters to this relation, orientating which is the best way to be followed and also estimating, as close as possible to the reality, the degree of impacts that can be caused. This paper studies a biodiesel plant in Brazil, using the model described in ISO's 14040 group to perform a life cycle inventory. Biodiesel is an alternative renewable fuel to the common diesel. The biodiesel has been considered a "clean" fuel, however its fabrication process involves environmental impacts. Hence, the objective of this study is to address those impacts, from a theoretical biodiesel plant data, and provide background information, in the form a life cycle inventory (LCI), to allow further comparisons between biodiesel production and other fuels. Finally, a full LCI for biodiesel is completed and it is concluded that, qualitatively, the environmental impact generated are similar to other commonly used fuels.
\end{abstract}

Keywords: Environmental Impacts, Life Cycle Inventory, Biodiesel, Biodiesel Production Unit

\section{Introduction}

The scarcity of fossil fuels, already announced in the coming decades [1] and its polluting effects on the environment, has led researchers and the scientific community to search for new energy options. In this scenario, there is the use of cleaner and renewable resources, such as biofuels.

One of the main reasons put forward to promote the use of biofuels, specifically ethanol and biodiesel, is the need to reduce emissions of greenhouse gases. Currently, much of the carbon dioxide emissions, responsible for the phenomenon mentioned, is due to the use of fossil fuels[2].

The diesel is a petroleum derivative that is widely used in the transport system in Brazil. Biodiesel is an alternative clean and is derived from renewable natural sources. The main advantage of the use of biodiesel is that it can be used directly in conventional engines, producing more nitrogen oxides, but in contrast, less oxides of carbon and particulate materials that diesel[3].

Brazil is a country with great potential for the production of clean fuels, since the area is extensive and the climate and soil are favorable. Therefore, there is a growing interest in research on biodiesel.

From this background, this work studied the life cycle inventory [5,6] of a biodiesel unit, under the scope of ISO 14.040[7] and ISO 14.044[8], in order to provide information regarding mass and energy balances, which can be used in further works to assess the life cycle of manufactory biodiesel.

However, studies have shown that the generation biofuels may cause further environmental impact that their fossil fuels [4].Given this context of environmental concern and potential of the country, this paper aims to explain quantitatively the environmental impacts in the production of biodiesel.

\section{Methodology}

This work is characterized by the pursuit of theoretical data for a plant to produce biodiesel. At this stage all data of mass and energy input and output of equipment were raised. This collection of raw data was converted in information through the modeling of the process. This modeling uses the data collected to describe the process according to the environmental management standards of ISO 14.040[7] and 
ISO 14044[8], as well as the process used by Haddad [5], which includes divide the process in smaller systems and analysis each subsystem. This phase is completed with the acquisition of inventories of inputs and outputs of each of these sub-systems.

\section{Case of Study}

This work follows the work done by Tapasvi et al. (2005) [9] and used by Costa (2009)[10], Hence the biodiesel production unit is as described in their work.

Firstly, it is required to deals with the process of data analysis as well as mass and utilities relative to the currents of energy and data devices. The flowchart of this process is shown in Figure1.

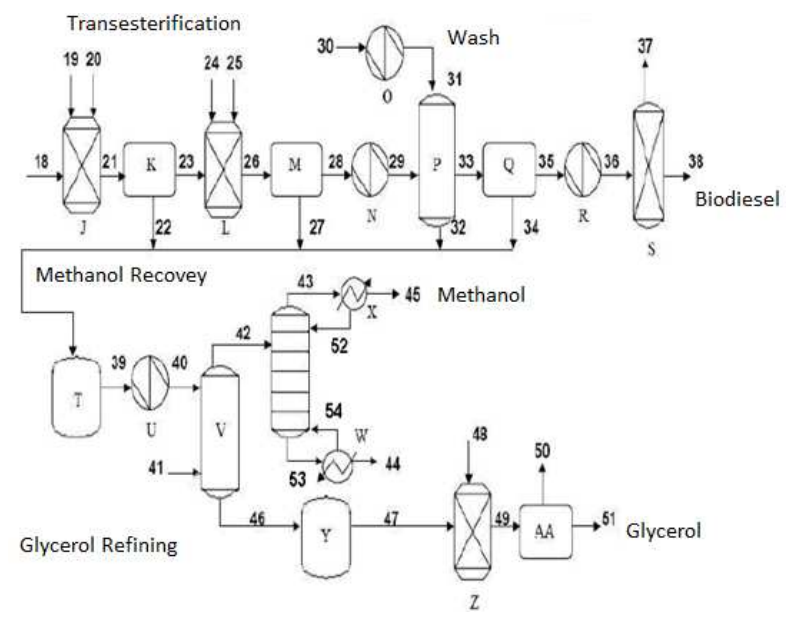

Figure 1. Flowchart of a Biodiesel Production Unit. Source: Costa (2009)[10]; Tapasvi et al. (2005)[9]

The production starts with the input stream(18) containing soybean refined oil in the first reactor "J" (Figure 1), which is maintained at atmospheric pressure and $60{ }^{\circ} \mathrm{C}$. Excess methanol is added in the stream 19. Stream 20 contains methanol and the catalyst, sodium methoxide.

The output of the reactor contains the unreacted compounds, sodium methoxide and the products, biodiesel and glycerol. The output stream 21 passes through the first decanter "K" (Figure 1), which separates it into two distinct phases: the first phase, containing glycerol, methanol and sodium methoxide and the second phase containing biodiesel, soybean oil and methanol. The first phase is sent to the methanol recovery center (stream 22), while the second (stream 23)continues to the next reactor "L" (Figure1).

The second reactor is kept under the same conditions as the first. As in the first reactor, methanol is admitted by stream 24 as well as 25 and sodium methoxide is admitted by the stream 25 (Figure 1). The products, the reactants and catalyst leaving the reactor (current 26)are led to the second decanter "M" (Figure 1). The phases are separated again. The glycerol phase (stream 27) follows to the methanol recovery unit, while the ester phase, stream 28 , is heated to $70^{\circ} \mathrm{C}$ before the wash step.
The stream 29 is washed with water at $70{ }^{\circ} \mathrm{C}$ from stream 31. The resulting aqueous phase, stream 32 containing methanol is taken to themethanol recovery unit, while the washed biodiesel in stream 33 is sent to the decanter "Q" (Figure1). In the decanter, the remaining aqueous phase is removed by gravity and is also sent to the treatment of the methanol (stream 34). Biodiesel, lighter than the aqueous phase, leaves the decanter(stream 35) and is heated to $95{ }^{\circ} \mathrm{C}$.

The biodiesel is finally sent to a vacuum dryer "S" (Figure1) to remove traces of moisture. The dryer operates at an absolute pressure of $4.7 \mathrm{kPa}$. The final product, stream 38, is $98 \%$ in biodiesel.

The streams 22, 27, 32, and 34 are collected in a tank "T" (Figure1). This mixture results in the stream 39, which is heated to $64.5^{\circ} \mathrm{C}$ (boiling point of methanol). Methanol is removed from the resulting current through the action of a stream 41 of water in a superheated stripper glycerol alcohol "V" (Figure1). Methanol and water are sent to the distillation column through the stream 42. The purified methanol in the tower is recovered by the stream 45 and is reused in the plant. The other compounds leaving the stripper (stream 46) are stored in the tank "Y" (Figure 1). This phase, rich in glycerol, is mixed with a solution of $\mathrm{HCl}$ (stream 48) in the reactor "Z" (Figure1).

In reactor "Z", sodium methoxide present in the glycerol rich stream reacts with the $\mathrm{HCl}$, forming $\mathrm{NaCl}$. If there is still oil in the glycerol stream, an organic salt can appear as a new product. The resulting stream of the reactor " $Z$ " (49) goes to a decanter "AA" (Figure1) which separates glycerol and other impurities.

This project is limited to the study of biodiesel production and separation and recovery of methanol. Glycerol is not considered a main product, and, for that reason, this study does not include the reactor "Z" and the decanter "AA" (Figure1).

\subsection{Streams Specifications}

With regard to the inventory of biodiesel, all data related to soybean oil were based upon the work developed by Costa (2009)[10].Soybean oil is a triglyceride composed of a number of fatty acids of different masses and different proportions as shown in Table 1.

Table 1.Raw material composition (soya oil)

\begin{tabular}{lllll}
\hline Fatty Acid & $\begin{array}{l}\text { Molecular } \\
\text { weight }\end{array}$ & C:N & \% mass & \% mol \\
\hline Palmitic & 256.43 & $16: 0$ & 11 & 11 \\
Estearic & 284.48 & $18: 0$ & 4 & 4 \\
Oleic & 282.47 & $18: 1$ & 23 & 23 \\
Linoleic & 280.47 & $18: 2$ & 54 & 54 \\
Linolenic & 278.44 & $18: 3$ & 8 & 8 \\
\hline
\end{tabular}

Source: Costa (2009)[10]; Hajbabaei et al. (2012)[12]

For the molecular weight of soybean oil, that is the basis of the inventory of the plant, equation (1) is used and nitrogen is not taken into account. 


$$
M(o i l)=3\left(\sum x_{i} M_{i}\right)+M_{C H-C-C H}
$$

where $M_{i}$ representsthe molecular weight of the fatty acid that has a mass fraction of $x_{i}$.

The biodiesel produced has the same composition of the fatty acids of the oil. So, its molecular weight is calculated by the same considerations made to the soybean oil, as exposed in equation (2).

$$
M(o i l)=3\left(\sum x_{i} M_{i}\right)+M_{C H 2}
$$

where $\mathrm{M}_{\mathrm{i}}$ represents the molecular weight of the fatty acid that has a mass fraction of $x_{i}$.

To determine the mass flows of process streams, a basis of $100 \mathrm{~kg} / \mathrm{h}$ of soybean oil of molecular weight 872.87 $\mathrm{g} / \mathrm{mol}$ (calculated as shown in Eq1) was used. Because trans esterificationis an equilibrium reaction, it isconsidered $100 \%$ excess of methanol to ensure $98 \%$ of total conversion, with conversion in the first reactor of $85 \%$ [9], [11]. Table 2 shows the data of each process stream, where the streams refer to the ones in Figure1.

\begin{tabular}{|c|c|c|}
\hline Stream & Compound & Flow (kg/h) \\
\hline \multirow{2}{*}{18} & Oil & 100 \\
\hline & Methanol & 22.02 \\
\hline \multirow{2}{*}{19} & Sodium methoxide & 1 \\
\hline & Methanol & 9 \\
\hline \multirow[t]{3}{*}{20} & Methanol & 13.02 \\
\hline & Oil & 15 \\
\hline & Biodiesel & 85.39 \\
\hline \multirow[t]{4}{*}{21} & Methanol & 12.66 \\
\hline & Glycerol & 8.97 \\
\hline & Sodium methoxide & 1 \\
\hline & Methanol & 7.6 \\
\hline \multirow[t]{3}{*}{22} & Sodium methoxide & 1 \\
\hline & Glycerol & 8.97 \\
\hline & Methanol & 5.06 \\
\hline \multirow[t]{2}{*}{23} & Oil & 15 \\
\hline & Biodiesel & 85.39 \\
\hline \multirow{2}{*}{24} & Sodium methoxide & 0.15 \\
\hline & Methanol & 1.35 \\
\hline \multirow[t]{3}{*}{25} & Methanol & 1.95 \\
\hline & Oil & 2 \\
\hline & Biodiesel & 98.45 \\
\hline \multirow[t]{4}{*}{26} & Methanol & 6.93 \\
\hline & Glycerol & 1.37 \\
\hline & Sodium methoxide & 0.15 \\
\hline & Methanol & 4.16 \\
\hline \multirow[t]{3}{*}{27} & Glycerol & 1.37 \\
\hline & Sodium methoxide & 0.15 \\
\hline & Methanol & 2.77 \\
\hline \multirow[t]{3}{*}{28} & Oil & 2 \\
\hline & Biodiesel & 98.45 \\
\hline & Methanol & 2.77 \\
\hline \multirow[t]{2}{*}{29} & Oil & 2 \\
\hline & Biodiesel & 98.45 \\
\hline 30 & Water & 19.69 \\
\hline 31 & Water & 19.69 \\
\hline \multirow{3}{*}{32} & Water & 17.72 \\
\hline & Methanol & 2.77 \\
\hline & Water & 1.97 \\
\hline \multirow[t]{2}{*}{33} & Oil & 2 \\
\hline & Biodiesel & 98.45 \\
\hline 34 & Water & 1.87 \\
\hline
\end{tabular}

Table 2.Mass flow of process streams

\begin{tabular}{lll}
\hline Stream & Compound & Flow $\mathbf{( k g} / \mathbf{h})$ \\
\hline 35 & Water & 0.1 \\
& Oil & 2 \\
& Biodiesel & 98.45 \\
36 & Water & 0.1 \\
& Oil & 2 \\
37 & Biodiesel & 98.45 \\
38 & Water & 0.1 \\
& Oil & 2 \\
& Biodiesel & 98.45 \\
39 & Water & 19.59 \\
& Sodium methoxide & 1.15 \\
& Glycerol & 10.34 \\
& Methanol & 14.53 \\
40 & Water & 19.59 \\
& Sodium methoxide & 1.15 \\
& Glycerol & 10.34 \\
41 & Methanol & 14.53 \\
42 & Steam & 218.76 \\
& Methanol & 14.53 \\
43 & Water & 238.35 \\
44 & Methanol & 62.23 \\
45 & Water & 0.04 \\
46 & Water & 239.53 \\
& Methanol & 13.35 \\
& Glycerol & 10.34 \\
& Sodium methoxide & 1.15 \\
\hline
\end{tabular}

Source: Costa (2009)[10]; Tapasvi et al. (2005)[9]

To determine the heat exchange of plant equipment, energy balance and enthalpy data were used [13]. Thethermal exchanges of process equipment are shown in Table 3. Besides, the steam used in equipment is shown in Table 4.

Table 3. Equipment energy

\begin{tabular}{lll}
\hline $\begin{array}{l}\text { Equipme } \\
\text { nt }\end{array}$ & Description & $\begin{array}{l}\text { Thermal exchange } \\
\text { rate (modulus) } \mathbf{( M J} / \mathbf{h})\end{array}$ \\
\hline $\mathrm{J}$ & Reactor & 128,4 \\
$\mathrm{~L}$ & Reactor & 19,4 \\
$\mathrm{~N}$ & Heater & 9,0 \\
$\mathrm{O}$ & Heater & 3,7 \\
$\mathrm{R}$ & Heater & 6,8 \\
$\mathrm{~S}$ & Vacuum dryer & 2,3 \\
$\mathrm{U}$ & Heater & 5,6 \\
$\mathrm{~W}$ & Distillation tower - Reboiler & 66,5 \\
$\mathrm{X}$ & Distillation tower - Condenser & 70 \\
\hline
\end{tabular}

Source: Costa (2009)[10]; Tapasvi et al. (2005)[9]

Table 4.Steam in equipment

\begin{tabular}{lll}
\hline Equipment & Description & Steam flow $\mathbf{( K g} / \mathbf{h})$ \\
\hline J & Reactor & 60,6 \\
L & Reactor & 9,2 \\
N & Heater & 4,3 \\
O & Heater & 1,7 \\
R & Heater & 3,2 \\
S & Vacuum dryer & 1,1 \\
U & Heater & 2,1 \\
W & Distillation tower - Reboiler & 33,3 \\
\hline
\end{tabular}

Source: Costa (2009)[10]; Tapasvi et al. (2005)[9] 


\section{Life CycleInventory - LCI}

The Life CycleInventory, LCI, isthemodelingpartofthe global analysisoftheprocess. [6, 14-17]. The LCI is carried out by mapping the process accordingly to the environmental management standards of ISO 14040 and 14.044 [7], [8]. The objective of this study is to get a quantitative LCI of a biodiesel plant compatible with the Brazilian reality.

\subsection{Scope Determination}

According to ISO 14040[7] and other sources [6], [14-17], to define the scope of a case of study, some aspects should be taken into consideration.Among them, we can point out the product system, the product function, system boundaries, and types of impacts and qualitative requirements of data. This topic talks about the aspects for scoping the process studied.

\subsubsection{Product Function \& Functional Unit}

It was defined that the function of the product is to provide biodiesel to be used as fuel. Therefore, it was necessary to establish a functional unit that meets the requirements of the product to be formed.

The generation of biodiesel $(98 \% \mathrm{~mol})$ was defined as a functional unit for developing the study. Once defined the functional unit, the mass quantities of reactants were set: 100 $\mathrm{kg} / \mathrm{h}$ of soybean oil mass $872.87 \mathrm{~g} / \mathrm{mol}$ and $100 \%$ excess of methanol.

The defined values are the basis for calculations of mass and energy streams in the process equipment. These calculations are also used in the stage of preparation of the Life Cycle Inventory and Impact Assessment.

\subsubsection{Product System}

For this plant, three subsystems were taken: the subsystem of biodiesel production, the methanol recovery subsystem and glycerol removal subsystem. The subsystems treated in this study involve all stages of the production plant, from the entry of the reactants to the purification of biodiesel and also the recovery of methanol and removal of glycerol.

It was decided to divide the plant into three units because the biodiesel production system operates independently, that is, the production does not need to be interrupted if the methanol recovery or glycerolremoval is inoperative.

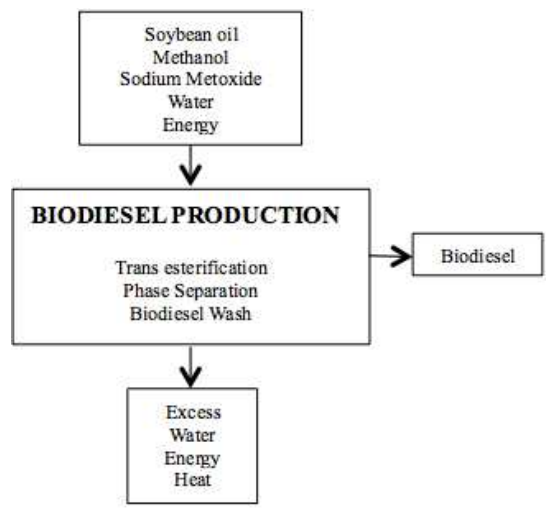

Figure 2. Biodiesel production subsystem. Source: Authors (2013)
The production starts with trans esterification reaction between soybean oil and methanol in the presence of sodium methoxide, as catalyst. The products, biodiesel and glycerol, and unconverted reactants are led to a series of separation's equipment in order to isolate biodiesel. The oily phase does not go to the next subsystem, the recovery of methanol.

For this subsystem, the inputs considered were the mass of soybean oil, methanol and sodium methoxide. We have also taken into account the use of water and electricity in the process. Water is used as the heat exchanger fluid for both heating and cooling, and as washing fluid. Electricity is required to operate the heaters, reactors and dryer.

\subsubsection{Methanol Recovery Subsystem}

The mixture separated from biodiesel, which contains the reactants methanol and unconverted soybean oil, the catalyst, sodium methoxide, and glycerol follows to the recovery of methanol. In this step, the mixture is treated in a stripper powered by superheated steam that separates methanol from glycerol-rich phase. The glycerol-rich phase goes to the next subsystem, the removal of glycerol.

A schematic draw of the methanol recovery subsystem based on the studied plant is shown in Figure 3.

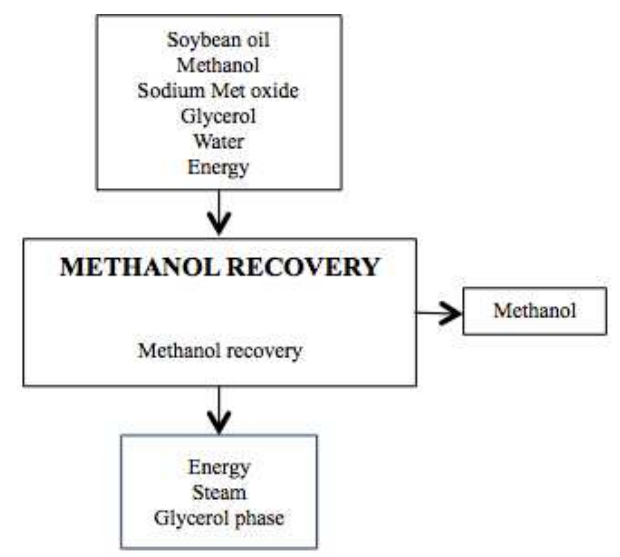

Figure 3.Methanol recovery subsystem. Source: Authors (2013)

\subsubsection{Biodiesel Production Subsystem}

A schematic draw of the biodiesel production subsystem based on the studied plant is shown in Figure 2.

For this subsystem, the inputs considered were the mass of soybean oil, methanol, glycerol and sodium methoxide, as well as the use of water, steam and electricity in the process. Water is used as the fluid heat exchanger both for heating and for cooling and steam is used in the stripper. Electricity is required to operate the heater and reboiler.

\subsubsection{Glycerol Removal Subsystem}

After the recovery of methanol, glycerol can be removed. In this study, it is only consideredthe suitable data for storing the glycerol-rich phase. The glycerol treatment is not a part of this subsystem.

\subsubsection{Boundaries of the Product System}

The steps of the product life cycle considered in this study only concern the systems of the plant. Production and 
transport of reactants, power generation, water production, and disposal of the products were not considered in the inventory.
Figure 4shows the included systems within the dotted boundary, and the excluded ones outside the dotted square.

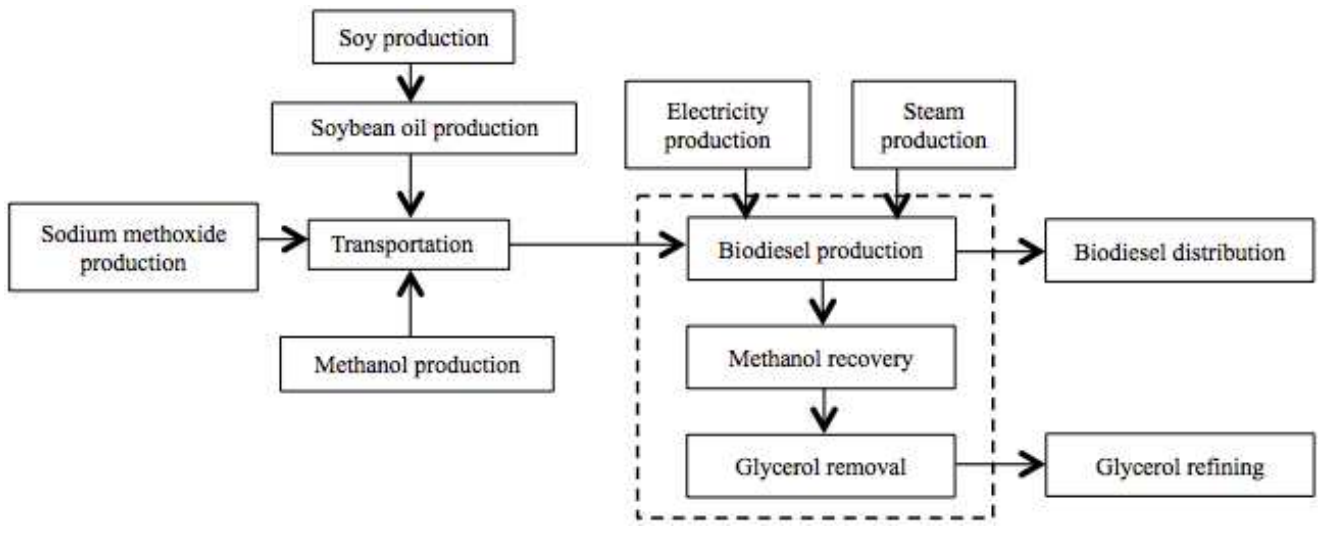

Figure 4. Boundaries of the System. Source: Authors (2013)

The subsystems included in the study as well as the excluded are presented in Table 5 .

Table 5. Included and excluded subsystems

\begin{tabular}{ll}
\hline Included subsystems & Excluded subsystems \\
\hline & Soybean production \\
& Soybean oil production \\
& Methanol production \\
Biodiesel production subsystem & Sodium methoxide production \\
Methanol recovery subsystem & Transportation \\
Glycerol removal subsystem & Electricity production \\
& Steam production \\
& Glycerol refining \\
& Biodiesel distribution \\
\hline
\end{tabular}

Source: Authors (2013)

\subsubsection{Types of Impact, Evaluation and Interpretation Methodologies}

In biodiesel production, energy from fuel oil is consumed in heaters, reboiler and dryer, and electric power is required to give equipment agitation.

The plant operates under mild conditions of temperature and pressure, i.e., the plant consumes few inputs that generate environmental impacts to keep these process conditions.

Methanol is a compound derived from petroleum that is toxic and must be treated before being stored or discarded. Besides, the generation of biodiesel also provides larges amount glycerol. As there are not many applications for this compound, this study will treat it as waste.

The plant uses water as an elementary steam. Among the advantages of using water in this process, we can point the availability of it in the country, its low cost and its high heat capacity. The fact that water has a high heat capacity causes a decrease in heating fuel, and that may reflect on the environmental impacts.

\subsubsection{Assumptions, Data, and Limitations}

It was determined that all inputs of mass and energy of each of the subsystems shall be considered in this study. In addition, all charges are included with the potential to produce damage to the environment.

\subsubsection{Quality Data Requirements}

Although theoretical, the data used in this study is representative in relation to the current production of biodiesel in Brazil.

Soybean was chosen to produce biodiesel because its oil has the biggest annual production among leguminous plants in Brazil. Besides, methanol is found in most of biodiesel's plants. The excesses and swings are also the same as those found in practice, as conversion.

It was not considered heat losses to the environment in equipment or piping or steam losses to the environment due to leaks or discharges. This study only reports the minimum energy required for operation of the plant.

\section{Inventory Analysis}

This topic deals with the preparation and analysis of inventories for each of the subsystems of the case of study. The inventories listed are the basis for the process of choosing the environmental indicator and simulation.

\subsection{Inventory of the Biodiesel Production Subsystem}

The biodiesel production subsystem receives the methanol, soybean oil and sodium methoxide needed to form the desired product. The mass input data of these compounds were based on stoichiometric calculations and information from literature.

The data concerning the production of energy and water vapor are part of another subsystem and are not discussed in this work. However, the energy used to operate plant equipment is calculated by charge balance, using the masses previously found.

Because the overall conversion of the reaction (first and second reactor) is set at $98 \%$, the process waste correspond to $2 \%$ of the total number of moles, which include reactants, catalyst, process water, glycerol and other wastes. That is, 
with the basis of $100 \mathrm{~kg} / \mathrm{h}$ of soybean oil of molecular weight $872.87 \mathrm{~g} / \mathrm{mol}$, it is generated $98.45 \mathrm{~kg}$ of biodiesel of molecular weight $292.30 \mathrm{~g} / \mathrm{mol}$ (eq 2) per hour and 2,39 moles of waste.

Table 6 shows the inputs of thesubsystem. Table 7 shows the output data of the subsystem.

Table 6.Inputs of the biodiesel production subsystem

\begin{tabular}{llll}
\hline & Compound & Quantity & Unit \\
\hline \multirow{2}{*}{ Reactants/Catalyst } & Soybean oil & 100 & $\mathrm{~kg} / \mathrm{h}$ \\
& Methanol & 47,34 & $\mathrm{~kg} / \mathrm{h}$ \\
& Sodium methoxide & 1,15 & $\mathrm{~kg} / \mathrm{h}$ \\
Energy & Electricity & 169,60 & $\mathrm{MJ} / \mathrm{h}$ \\
& Heating fuel & 24,21 & $\mathrm{~kg} / \mathrm{h}$ \\
Elementary Flows & Water & 19,69 & $\mathrm{~kg} / \mathrm{h}$ \\
& Steam & 80,10 & $\mathrm{~kg} / \mathrm{h}$ \\
\hline
\end{tabular}

Source: Authors (2013)

Table 7.Outputs of the biodiesel production subsystem

\begin{tabular}{llll}
\hline & Compound & Quantity & Unit \\
\hline \multirow{2}{*}{ Products } & Biodiesel & 98,45 & $\mathrm{Kg} / \mathrm{h}$ \\
& Glycerol & 10,34 & $\mathrm{Kg} / \mathrm{h}$ \\
& Soybean oil & 2 & $\mathrm{~kg} / \mathrm{h}$ \\
\multirow{5}{*}{ Excess } & Methanol & 14,53 & $\mathrm{~kg} / \mathrm{h}$ \\
& Sodium methoxide & 1,15 & $\mathrm{~kg} / \mathrm{h}$ \\
& Water & 19,69 & $\mathrm{~kg} / \mathrm{h}$ \\
\hline
\end{tabular}

Source: Authors (2013)

\subsection{Inventory of the Methanol Recovery Subsystem}

The recovery subsystem receives excess methanol, glycerol, and water and sodium methoxide from thebiodiesel production subsystem. Those input data are listed in Table 8, while the output data from the addressed subsystem are presented in Table 9.

Table 8.Inputs of the methanol recovery subsystem

\begin{tabular}{llll}
\hline & Compound & Quantity & Unit \\
\hline Compounds & Methanol & 14,53 & $\mathrm{~kg} / \mathrm{h}$ \\
from biodiesel & Sodium methoxide & 1,15 & $\mathrm{~kg} / \mathrm{h}$ \\
production & Water & 19,69 & $\mathrm{~kg} / \mathrm{h}$ \\
subsystem & Glycerol & 10,34 & $\mathrm{~kg} / \mathrm{h}$ \\
& Electricity & 72,20 & $\mathrm{MJ} / \mathrm{h}$ \\
Energy & Heating fuel & 18,42 & $\mathrm{~kg} / \mathrm{h}$ \\
Elementary & Heating water & 36,00 & $\mathrm{~kg} / \mathrm{h}$ \\
flows & Steam & 218,76 & $\mathrm{~kg} / \mathrm{h}$ \\
\hline
\end{tabular}

Source: Authors (2013)

Table 9. Outputs of the methanol recovery subsystem

\begin{tabular}{llll}
\hline & Compound & Quantity & Unit \\
\hline Product & Methanol & 13,35 & $\mathrm{~kg} / \mathrm{h}$ \\
& Glycerol & 10,34 & $\mathrm{~kg} / \mathrm{h}$ \\
\multirow{2}{*}{ Excess } & Sodium methoxide & 1,15 & $\mathrm{~kg} / \mathrm{h}$ \\
& Water & 239,53 & $\mathrm{~kg} / \mathrm{h}$ \\
\hline
\end{tabular}

Source: Authors (2013)

\subsection{Inventory of the Glycerol Removal Subsystem}

The subsystem receives the excess glycerol, water and sodium methoxide from the methanol recovery subsystem. In this subsystem, glycerol is treated to be isolated. Energy, fuel, and other reagents are not included in this study. Table 10 shows the inputs and outputs of this subsystem.

Table 10. Flows of the glycerol removal subsystem

\begin{tabular}{lllll}
\hline & & Compounds & Quantity & Unit \\
\hline $\begin{array}{l}\text { Inlet } \\
\text { flow }\end{array}$ & $\begin{array}{l}\text { Compound from } \\
\text { the methanol } \\
\text { recovery } \\
\text { subsystem }\end{array}$ & $\begin{array}{l}\text { Sodium } \\
\text { methoxide }\end{array}$ & 1,15 & $\mathrm{~kg} / \mathrm{h}$ \\
& Product & Glycerol & 10,34 & $\mathrm{~kg} / \mathrm{h}$ \\
$\begin{array}{l}\text { Outlet } \\
\text { flow }\end{array}$ & Excess & Glycerol & 10,34 & $\mathrm{~kg} / \mathrm{h}$ \\
& & $\begin{array}{l}\text { Sodium } \\
\text { methoxide }\end{array}$ & 1,15 & $\mathrm{~kg} / \mathrm{h}$ \\
\hline
\end{tabular}

Source: Authors (2013)

\section{Conclusion}

This study addressed the inventory of the life cycle of a biodiesel plant from data extracted from a theoretical production. There are two aspects that have led to interest in this research: First, the growing environmental concern, and second, the strategic position of Brazil in relation to biofuels production.

Although the inventory is based on the Brazilian reality, Brazil still does not have a consolidated database for the simulation. The use of the American database, however, does not affect the study since this is just a theoretical estimative of a plant.

The main contribution of this work is to provide a LCI for biodiesel production consistent with the reality in Brazil, thus allowing future works aiming LCA of such process.

\section{References}

[1] R. Brecha, "Ten Reasons to Take Peak Oil Seriously," Sustainability, vol. 5, no. 2, pp. 664-694, Feb. 2013.

[2] M. A. Oehlschlaeger, "Prospects for Biofuels: A Review," $J$. Therm. Sci. Eng. Appl., vol. 5, no. 2, p. 021006, May 2013.

[3] S. Liu, H. Jia, B. Yin, Z. Xu, and T. Guan, "Investigation on Combustion Characteristics of Direct Injection Nature Inhale Diesel Engine Fuelled with Biodiesel," 2009 AsiaPacific Power Energy Eng. Conf., vol. 2, pp. 38-41, 2010.

[4] A. Holma, K. Koponen, R. Antikainen, L. Lardon, P. Leskinen, and P. Roux, "Current limits of life cycle assessment framework in evaluating environmental sustainability - case of two evolving biofuel technologies," $J$. Clean. Prod., vol. 54, pp. 215-228, Sep. 2013.

[5] A. N. Haddad, K. Condeixa, M. Sedrez, A. C. J. Evangelista, and D. T. Boer, "Quality Indicators for Life Cycle Inventory: Real Cases Exploratory Application," Appl. Mech. Mater., vol. 431, pp. 350-355, Oct. 2013. 
[6] G. Sonnemann, B. Vigon, C. Broadbent, M. A. Curran, M. Finkbeiner, R. Frischknecht, A. Inaba, A. Schanssema, M. Stevenson, C. M. L. Ugaya, H. Wang, M.-A. Wolf, and S. Valdivia, "Process on 'global guidance for LCA databases'," Int. J. Life Cycle Assess., vol. 16, no. 1, pp. 95-97, Dec. 2010.

[7] ISO, ISO 14040 International Standard. Environmental management - Life cycle assessment - Principles and framework. Geneva, Switzerland.: International Organisation for Standardization, 2006.

[8] ISO, ISO 14044 - Environmental Management: Life Cycle Assessment, Life Cycle Impact Assessment. Geneva, Switzerland.: International Organisation for Standardization, 2006.

[9] D. Tapasvi, D. Wiesenborn, and C. Gustafson, "Process model for biodiesel production from various feedstocks.," Trans. ASAE, 2005.

[10] R. A. B. Costa, "ESTUDO DAS EFICIÊNCIAS DE OPERAÇÃO E CONSUMO DE ENEGRIA EM PLANTAS DE BIODIESEL," 2009.

[11] R. A. B. Costa, "ESTUDO DAS EFICIÊNCIAS DE OPERAÇÃO E CONSUMO DE,” 2009.

[12] M. Hajbabaei, K. C. Johnson, R. A. Okamoto, A. Mitchell, M.
Pullman, and T. D. Durbin, "Evaluation of the impacts of biodiesel and second generation biofuels on $\mathrm{NO}(\mathrm{x})$ emissions for CARB diesel fuels.," Environ. Sci. Technol., vol. 46, no. 16, pp. 9163-73, Aug. 2012.

[13] A. Demirbas, "Relationships derived from physical properties of vegetable oil and biodiesel fuels," Fuel, vol. 87, no. 8-9, pp. 1743-1748, Jul. 2008.

[14] O. Ortiz, F. Castells, and G. Sonnemann, "Sustainability in the construction industry: A review of recent developments based on LCA," Constr. Build. Mater., vol. 23, no. 1, pp. 28-39, Jan. 2009.

[15] V. Cappuyns, "LCA based evaluation of site remediation: Opportunities and limitations," Chim. Oggi/Chemistry Today, vol. 31 , no. 2, pp. 18-21, 2013.

[16] G. Finnveden, P. Eldh, and J. Johansson, "Weighting in LCA based on ecotaxes: Development of a mid-point method and experiences from case studies," Int. J. Life Cycle Assess., vol. 11, no. SPEC. ISS. 1, pp. 81-88, 2006.

[17] G. Guest, R. M. Bright, F. Cherubini, and A. H. Strømman, "Consistent quantification of climate impacts due to biogenic carbon storage across a range of bio-product systems," Environ. Impact Assess. Rev., vol. 43, pp. 21-30, Nov. 2013. 